Original Research

\title{
Improved Dissolved Air Flotation Performances Using Chitosan under Different Dosing Schemes
}

\author{
Yu-Long Shi, Jun Ma*, Jia-Xuan Yang \\ State Key Laboratory of Urban Water Resource and Environment, School of Municipal \\ and Environmental Engineering, Harbin Institute of Technology, \\ Harbin 150090, China
}

Received: 4 January 2017

Accepted: 15 May 2017

\begin{abstract}
In the present work we investigated the applications of chitosan as a bubble surface modifier in the coagulation dissolved air flotation (DAF) process for river water treatment. Zeta potentials of the residual colloidal particles in floated water and other typical water quality indexes measurements reinforced the fact that micro-bubble surface was successfully modified by dosing chitosan in a saturation system. The flotation efficiencies of both natural organic matters (NOM) and particles were obviously enhanced via chitosanmodified bubbles and the effects became more remarkable after the $\mathrm{pH}$ of saturation water was adjusted from 7.0 to 5.5, especially for NOM removal. Moreover, the influence of chitosan on DAF performance, as a coagulant aid, was also evaluated. The coagulation-aiding effects of chitosan were equal to acting as a bubble modifier at $\mathrm{pH} 7.0$, but less efficient than the bubble modification $\mathrm{DAF}$ at $\mathrm{pH}$ 5.5. In addition, the effects of molecular weight (MW) and deacetylation degree (DD) of chitosan on its performance in both dosing strategies were discussed in detail. These findings highlight the advantages of bubble surface modification in surface water treatment and provide an alternative for DAF process optimization.
\end{abstract}

Keywords: bubble surface modification, chitosan, deacetylation degree, dissolved air flotation, molecular weight

\section{Introduction}

The application of advanced oxidation processes and biological filtration for the removal of natural organic matter is a hot research topic [1-2]. But the chemical oxidation and biodegradation of NOM will lead to the the production of carbon dioxide, which is the primary greenhouse gas and a threat to human health beyond a threshold level [3-7]. By contrast, sedimentation and flotation are the most common and economically feasible

*e-mail:majun@hit.edu.cn units used to remove natural organic matters (NOM) and colloid particles in surface water treatment [8]. Flotation has been used for waste water reclamation [9], and this has the good prospects of practical applications, especially in drought areas [10]. Concerning sedimentation and flotation processes, efficient coagulation is an essential prerequisite. Over the ordinary $\mathrm{pH}$ range, the NOM components and particles bear a negative charge [11]. In order to accomplish a superior removal of NOM, enhanced coagulation is proposed as the best available technique by adding acid/base or increasing dosage of metal coagulants [12]. But both methods have disadvantages, such as increasing the corrosivity of treated water [13] and causing 
human health problems related to the high aluminum residuals in tap water [14].

Recently, a new innovation has focused on coagulant optimization, which has been considered to be the third available way for enhanced coagulation [15]. Researchers prepared composited coagulants through a combination of inorganic coagulant and polymer additives with the intent of taking the advantages of both components, such as composite polyaluminum chloride (HPAC) [15], preformed polyferric chloride- polyDADMAC coagulant [16], and a novel polyaluminum-chitosan compound [17]. Although these new complex reagents exhibit superior coagulation effects over conventional metallic coagulants, most of them are still in the development stage.

Besides enhanced coagulation, there is another approach for DAF to improve its performances. As a unique participant, the enormous amounts of micro-bubbles, undertaking all tasks of floc-particles separation, recently excited the particular interest of researchers. The bubble surface zeta potential was considered to be an essential factor for its interaction with floc particles. A series of studies were conducted to optimize the bubble surface characteristics. Results proved that the negatively charged bubble surface could be positively modified using cationic chemicals [18-21]. Bubble surface positive modification may be a novel way to improve DAF performance in pollutant control. More recently, Rao et al. obtained the positively charged bubbles by dosing aromatically modified polymers in the saturator to separate algae cells [22]. Zhang and Guiraud demonstrated the utilization of positive bubble surfaces for silica nanoparticle separation, and the optimum removal rate was beyond $90 \%$ [23]. In our previous study the feasibility of bubble modification was also confirmed and the surface-modified bubbles exhibited significant potential to combine with coagulation pretreatment for river water treatment [24].

In this work, based on the conventional coagulationDAF process (conv.DAF) coagulation with polyaluminum chloride $(\mathrm{PACl})$, the performance of bubble positive modification DAF (posi.DAF) was investigated during river water treatment. Chitosan, a cationic natural biopolymer, was selected as the bubble surface modifier due to its non-toxicity, high biodegradability, and ecological friendliness [25]. The primary purpose of this study was to determine the optimum dosing strategy for this posi.DAF system. For comparison, the flotation efficiency using chitosan as flocculation aids was also examined. In addition, the influences of the DD and MW on chitosan flotation aiding effects were evaluated in these two different dosing schemes.

\section{Materials and Methods}

\section{Materials}

All chemicals used were of analytical grade or higher, except the $\mathrm{PACl}\left(\mathrm{Al}_{2} \mathrm{O}_{3}\right.$ content $\left.30.5 \%\right)$, which was produced by Gongyi Fuyuan Water Purification Material Co., Ltd., China. Three native chitosans with medium or high molecular weight (MMW or HMW) and medium or high deacetylation degree (MDD or HDD) were provided by Jinan Haidebei Marine Bioengineering Co., Ltd., China. The molecular weight of chitosan is determined in terms of the Mark-Houwink equation, and the intrinsic viscosity was measured by a Ubbelohde viscometer. The degree of deacetylation was determined by acid-base titration. The charge density of cationic polymers was quantified by the colloid titration method based on the procedure proposed by Kam and Gregory using potassium polyvinyl sulphate (PPVS) calibrated by standard reagent CTAB [26]. The properties of chitosans are summarized in Table 1. Stocking solution of Chitosan $1 \mathrm{~g} / \mathrm{L}$ was prepared with $0.025 \mathrm{M} \mathrm{HCl}$ and overnight stirring at room temperature $\left(25^{\circ} \mathrm{C}\right)$ before dosing. Other reagents were purchased from Sinopharm Chemical Reagent Co., China.

\section{Experimental Set-up}

A column DAF was employed in this work, located at a waterworks along the Huai River (HR). The unit was mainly composed of a multiphase pump (20FPD05 Nikuni, Japan), a stainless steel air-liquid separation vessel, a recycled water tank, and four transparent acrylic columns (Fig. 1). Each column installed a blade stirrer with automatic timer and mixing speed control.

The experiments of posi.DAF via chitosan were carried out as follows:

1. Coagulation/Flocculation - Tests were performed with $4 \mathrm{~L}$ raw water transferred into each column. A given volume of $\mathrm{PACl}$ working solutions were added in columns using a pipette, and immediately the stirring apparatus were operated as the following procedures: rapid mixing at $500 \mathrm{rpm}$ for $1 \mathrm{~min}$, then gentle stirring at $100 \mathrm{rpm}$ for $5 \mathrm{~min}$.

2. Bubble generation - Filtered water of the waterworks was transferred into the DAF recycle water tank and the $\mathrm{pH}$ value (e.g., $7.0 \pm 0.1,5.5 \pm 0.1$ ) was adjusted using $0.2 \mathrm{M} \mathrm{HCl}$ solutions. The chitosan working solution was added to the recycle tank and mixed evenly. Then the DAF pump started up. The recycled water was saturated with air at pressure of $500 \mathrm{kPa}$ for

Table 1. Characteristics of chitosans used in the tests.

\begin{tabular}{|c|c|c|c|}
\hline Polymer & Molecular weight $(\mathrm{g} / \mathrm{mol})$ & Deacetylation degree $(\%)$ & Charge density $(\mathrm{meq} / \mathrm{g})$ \\
\hline Ch.HMW HDD & 510,900 & 87.8 & $4.5(\mathrm{pH} 5.5) 2.3(\mathrm{pH} \mathrm{7})$ \\
\hline Ch.HMW MDD & 507,200 & 76.5 & $3.6(\mathrm{pH} \mathrm{5.5)} \mathrm{1.8} \mathrm{(pH} \mathrm{7)}$ \\
\hline Ch.MMW MDD & 218,000 & 75.9 & $3.2(\mathrm{pH} \mathrm{5.5)} \mathrm{1.5} \mathrm{(pH} \mathrm{7)}$ \\
\hline
\end{tabular}




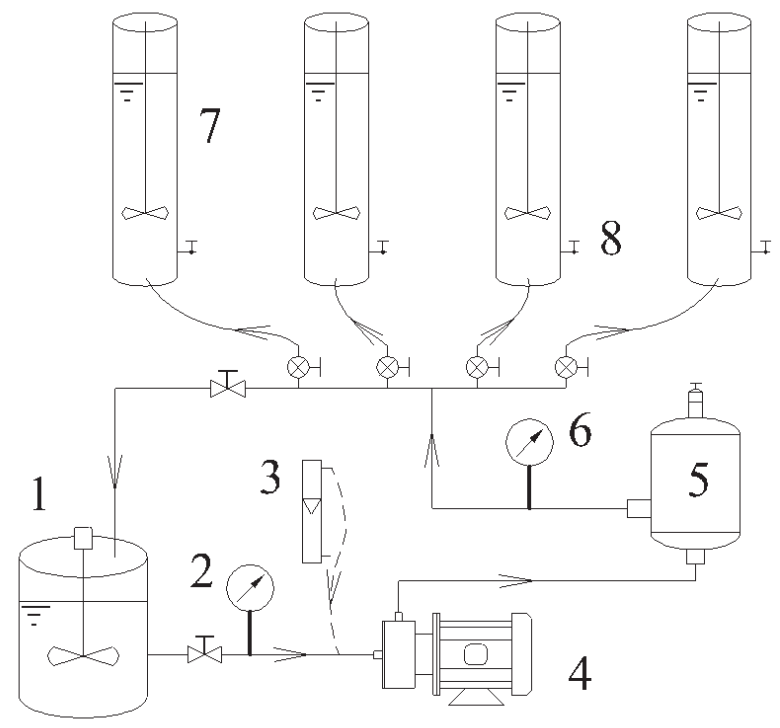

Fig. 1. Schematic diagram of DAF pump system: 1) recycled water tank, 2) vacuometer, 3) air rotameter, 4) multiphase pump, 5) air-liquid separation vessel, 6) manometer, 7) flotation column, 8) sampling point.

$2 \mathrm{~min}$. Finally, microbubbles were introduced into the columns via a releasing device under an equivalent recycling ratio of $10 \%$. After 15 min flotation, samples were collected from the bottom of the column for further analysis. If chitosan was used as a coagulant aid, its dosing point changed to the flotation columns under different sequences with $\mathrm{PACl}$. Other procedures remained unchanged.

\section{Raw Water}

Source waters for DAF tests were collected from the HR, located in central China between the Yangtze and Yellow rivers. The raw water dissolved organic carbon (DOC) level was generally around $5.4 \mathrm{mg} / \mathrm{L}$ with $\mathrm{UV}_{254}$ absorbance of $0.12 \mathrm{~cm}^{-1}$, both of which determined a relatively lower value of the specific ultraviolet absorbance (SUVA) of about 2.2. This indicated that the organic matters in HR were a mixture of aromatic humic substances and aliphatic non-humic matters [11]. The raw water showed a moderate to high alkalinity level, maintaining above $105 \mathrm{mg} / \mathrm{L}$ as $\mathrm{CaCO}_{3}$. The $\mathrm{pH}$ values varied between 7.3 and 7.5. In addition, during this work the raw water turbidity remained under $70 \mathrm{NTU}$ at $22.8^{\circ} \mathrm{C}$ on average.

\section{Analytical Methods}

Total organic carbon (TOC) was analyzed using prepared reagents based on the persulfate oxidation photometric principle (HACH Standard Method 10129), with the assistance of a HACH DR5000 UV-Vis spectrophotometer and Digital Reactor Block 200. DOC was analyzed according to the same method after samples were filtrated through a polycarbonate membrane of
$0.45 \mu \mathrm{m}$ pore size. $\mathrm{UV}_{254}$ was determined by DR5000 after samples were filtrated through a $0.45 \mu \mathrm{m}$ syringe filter. Turbidity was measured by a $\mathrm{HACH} 2100 \mathrm{~N}$ turbidimeter. $\mathrm{pH}$ was measured using a PHS-3C $\mathrm{pH}$ meter (Leici Shanghai, China). Zeta potential of suspended particles in floated water was measured using a JS94H micro-electrophoresis instrument (POWEREACH, China). All tests were performed in duplicate and the average error between replicates was always under $5 \%$.

\section{Results and Discussion}

\section{Chitosan Modification DAF with Coagulation Pretreatment}

\section{Effect of [CH]:[Al] Ratios}

The flotation efficiencies for HR water treatment at different chitosan-to-aluminum concentration ratios ([CH]:[Al]) are shown in Fig. 2. The pH of recycled water was kept at $7 \pm 0.1$ during the experiments. As can be seen compared with the conv.DAF, the introduction of chitosan-modified bubbles in posi.DAF obviously enhanced DOC and turbidity removal. The promotion effects decreased with the increase of $\mathrm{PACl}$ dosage (in term of $\mathrm{Al}$ concentration). For example, at $[\mathrm{CH}]:[\mathrm{Al}]$ ratio of 0.4 and with a low $\mathrm{Al}$ concentration $(1 \mathrm{mg} / \mathrm{L})$, the removal rates of turbidity and DOC were improved by about $20.7 \%$ and $8 \%$, respectively. While with moderate $\mathrm{Al}$ concentration $(4 \mathrm{mg} / \mathrm{L})$ their increase dropped to $7.3 \%$ and $4.3 \%$. Under the same $\mathrm{Al}$ concentration, with the $[\mathrm{CH}]:[\mathrm{Al}]$ ratio rising from 0.2 to 0.4 , there was a positive correlation between the DOC removal rate and chitosan dosage. But for turbidity control there was no remarkable improvement.

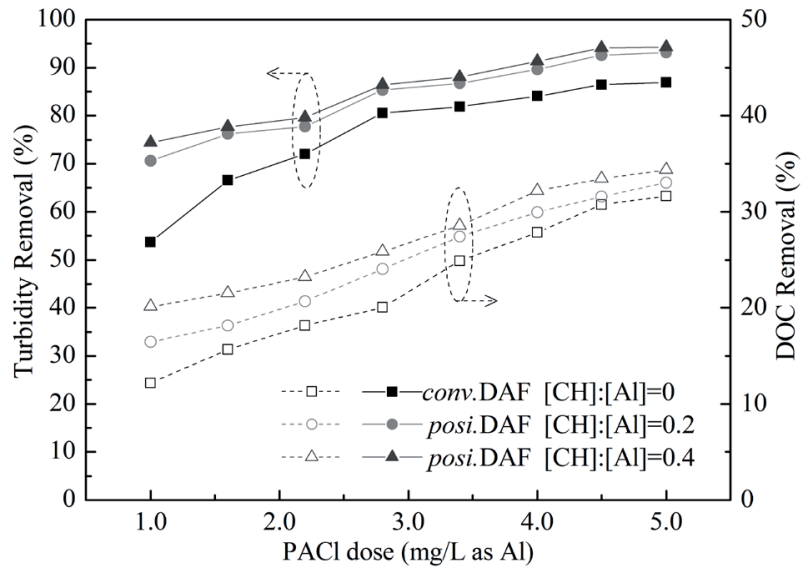

Fig. 2. Turbidity and DOC removal by conv.DAF and posi.DAF at different $[\mathrm{CH}]:[\mathrm{Al}]$ ratios (raw water quality: DOC $5.32 \mathrm{mg} / \mathrm{L}$, $\mathrm{UV}_{254} 0.131 \mathrm{~cm}^{-1}$, turbidity $54.8 \mathrm{NTU}, 23.2^{\circ} \mathrm{C}$; recycled water pH: $7 \pm 0.1)$. 


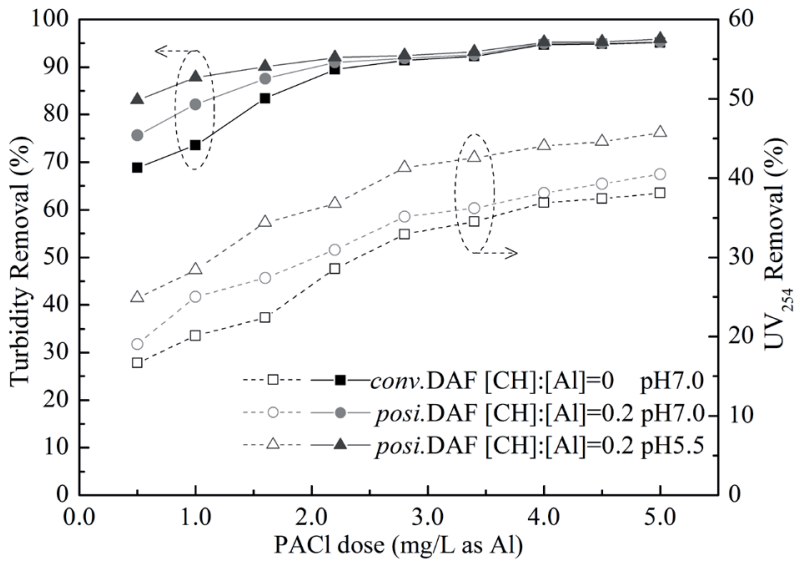

Fig. 3. Turbidity and $\mathrm{UV}_{254}$ removal by conv.DAF and posi.DAF with recycled water at $\mathrm{pH} 7.0$ and 5.5 (raw water quality: DOC $5.20 \mathrm{mg} / \mathrm{L}, \mathrm{UV}_{254} 0.119 \mathrm{~cm}^{-1}$, turbidity $29.3 \mathrm{NTU}, 23.5^{\circ} \mathrm{C}$ ).

\section{Effects of the Recycled Water $p H$ Values}

As illustrated in Fig. 3, posi.DAF performed more effectively at $\mathrm{pH} 5.5$ than at $\mathrm{pH} 7.0$, especially for the organic matters separation. The change tendency accorded well with the results of the previous modifiers selection tests [24]. Compared with $\mathrm{UV}_{254}$, the optimal removal of turbidity was first obtained. At the Al concentration of $4 \mathrm{mg} / \mathrm{L}$, the maximum turbidity removal of $95 \pm 0.3 \%$ was successively reached for all dosing schemes, beyond which the residual turbidity of the floated water remained unchanged. By contrast, there was an obvious improvement of $\mathrm{UV}_{254}$ reduction with its average removal percentage increasing from $32.4 \%$ at $\mathrm{pH} 7.0$ to $38.1 \%$ at $\mathrm{pH} 5.5$.

The $\mathrm{pH}$ dependence of posi.DAF on NOM removal was closely related to the $\mathrm{pH}$ sensitive charge density of chitosan. The protonation degree of $-\mathrm{NH}_{2}$ groups along the backbone of chitosan determined its positive charge

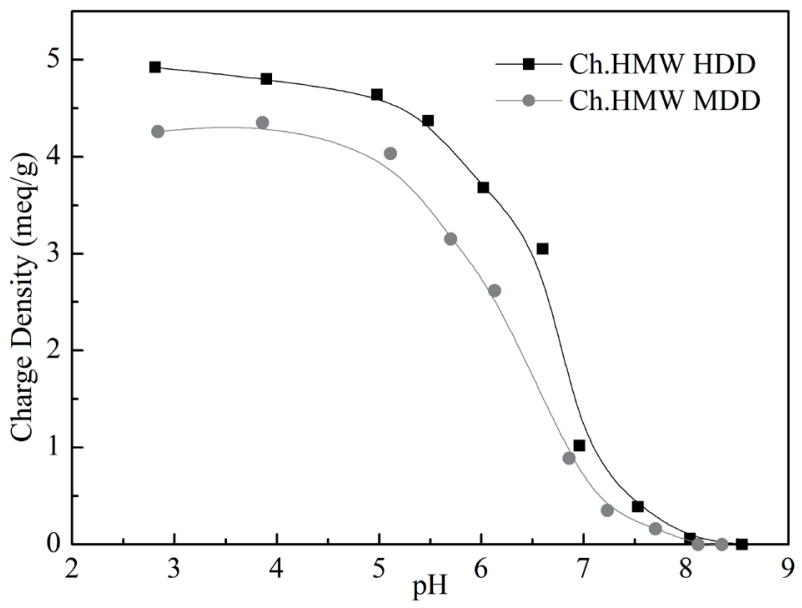

Fig. 4. Effect of $\mathrm{pH}$ on charge density of high molecular weight chiotsan (HMW) with medium/high deacetylation degree (MDD or HDD). density and also the bubble interfacial properties covered with it. The pKa value of the amino group was about 6.3 [25]. It can be considered that a small proportion or most of the amino groups were protonated at $\mathrm{pH} 7.0$ and 5.5, respectively. As seen in Fig. 4, when $\mathrm{pH}$ is below 5.0 the cationic charge of chitosans sustained high levels, then sharply decreased with $\mathrm{pH}$ increasing from 5.5 to 7.0 and became almost zero at $\mathrm{pH}$ around 8.0. Thus the adjustment of $\mathrm{pH}$ from 7.0 to 5.5 facilitated the electrostatic interactions between the oppositely charged modification bubbles and organic matter. In addition, the different removal characteristic between $\mathrm{UV}_{254}$ and turbidity also revealed that charge neutralization played an important role in organic matter separation.

\section{Zeta Potentials of Floated Samples}

The zeta potentials of the residual particles after flotation are shown in Fig. 5. For conv.DAF, the zeta potential increased steadily following the charge neutralization between hydrolyzed Al species and pollutants. The extra addition of chitosan as bubble surface modifiers in posi.DAF at $\mathrm{pH} 7.0$ did not obviously elevate the zeta potential. When dosing chitosan in a recycled water tank at $\mathrm{pH} 5.5$, the main difference was that the introduction of acidic white water would lower the $\mathrm{pH}$ of finished water. Although this decrease was not distinct (0.3-0.6 pH units), it might theoretically lead to an increase of the cationic charge of chitosan and amplify the effect of residual chitosan on the zeta potentials. This supposition, however, wasn't proved by test results. We can see that the zeta potential after the acidic recycle water leading-in had no obvious promotions and followed nearly the same profile as the other two dosing plans. This indicated that the majority of chitosan can be tightly bonded with bubbles and only a little remained in the bulk water, which agreed well with the previous results that chitosan strongly bound onto the bubble surfaces under various $\mathrm{pH}$ conditions through electrostatic

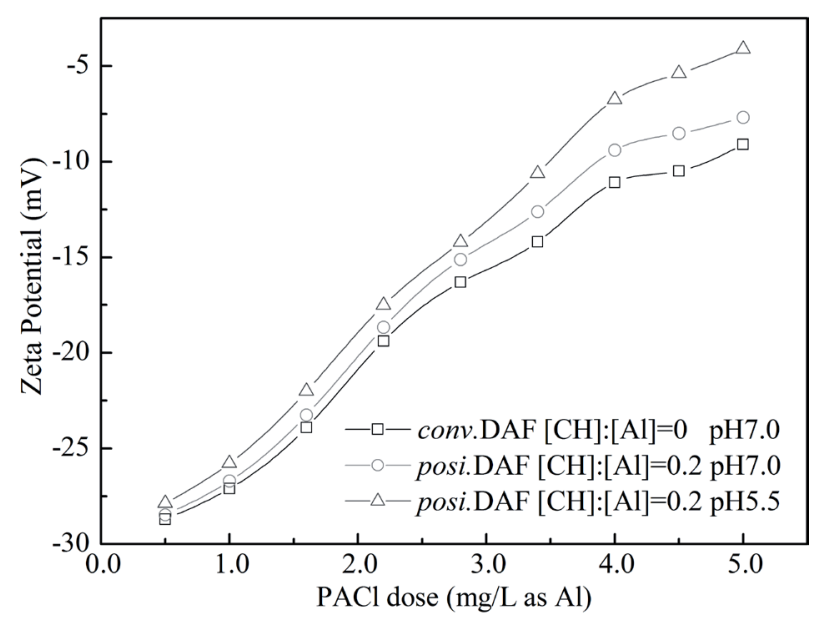

Fig. 5. Zeta potentials of floated water for conv.DAF and posi. DAF with recycled water at $\mathrm{pH} 7.0$ and 5.5 (raw water quality: DOC $5.20 \mathrm{mg} / \mathrm{L}, \mathrm{UV}_{254} 0.119 \mathrm{~cm}^{-1}$, turbidity $29.3 \mathrm{NTU}, 23.5^{\circ} \mathrm{C}$ ). 
interaction, hydrophobic attraction, and hydrogen bonding [24].

\section{Influence of MW and DD on Chitosan Performance}

\section{Molecular weight (Ch.MMW MDD versus Ch.HMW MDD)}

Molecular weight and deacetylation degree are two important characteristics of chitosan playing a subtle role in its interaction with dissolved and colloidal pollutants. In order to study the effects of MW and DD of chitosan on posi.DAF performances, a complementary experiment was conducted. In all trials, the $\mathrm{pH}$ of recycled water and $[\mathrm{CH}]:[\mathrm{Al}]$ ratio were kept at $5.5 \pm 0.1$ and 0.2 , respectively. Results showed that a much higher MW of chiotsan was favorable for bubble flotation. For example, the removal rate of $\mathrm{UV}_{254}$ increased from $26.6 \%$ to $29.7 \%$ with the MW increase from $2.18 \times 10^{5} \mathrm{~g} / \mathrm{mol}$ to $5.11 \times 10^{5} \mathrm{~g} / \mathrm{mol}$ at $\mathrm{PACl}$ dosage of $2 \mathrm{mg} / \mathrm{L}$. As is well known, increasing polymer MW can strengthen its bridging adsorption ability. But when chitosan was used as a bubble surface modifier, there was another important derivative effect that the higher the chitosan MW, the more readily it adsorbed onto the bubble surface.

\section{Deacetylation Degree (Ch.HMW MDD versus Ch.HMW HDD)}

The deacetylation degree of chitosan was intimately associated with its rheological behavior and also determined the distribution of cationic sites along its backbone. The higher DD of chitosan meant that more amino groups could be activated. When the $\mathrm{pH}$ of the recycled water was decreased to 5.5, the removal efficiency of $\mathrm{UV}_{254}$ was obviously improved by the increase of DD. For Ch.HMW, with its DD rising from $76.5 \%$ to $87.8 \%$, the $\mathrm{UV}_{254}$ removal rates increased by $4.7 \%$ at $\mathrm{Al}$ concentration

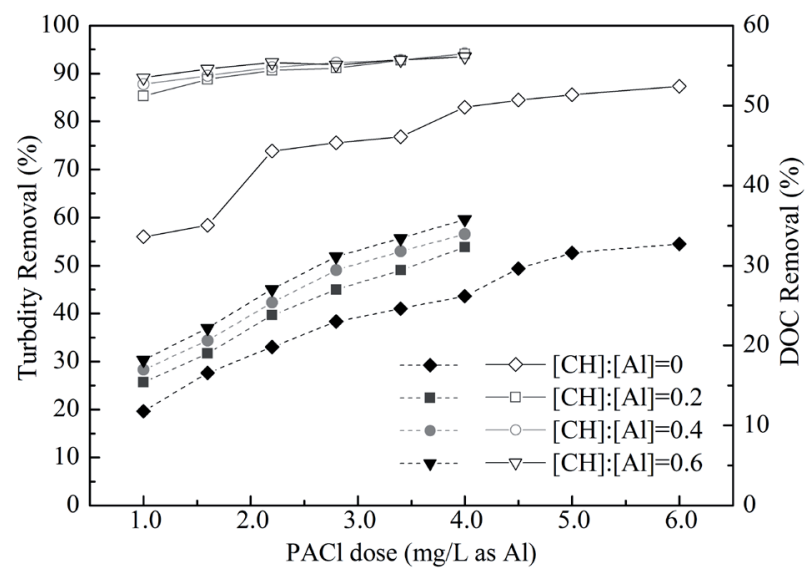

Fig. 6. Flotation efficiency of turbidity (solid line) and DOC (dashed line) in dual-coagulant strategies at different [CH]:[Al] ratios (raw water quality: DOC $5.16 \mathrm{mg} / \mathrm{L}, \mathrm{UV}_{254} 0.110 \mathrm{~cm}^{-1}$, turbidity $42.5 \mathrm{NTU}, 24.1^{\circ} \mathrm{C}$; recycled water $\mathrm{pH}: 7 \pm 0.1$ ). of $5 \mathrm{mg} / \mathrm{L}$. The very reason for the more efficient performance of Ch.HDD than Ch.MDD can be found in Fig. 4. The Ch.HDD exhibited a higher positive charge density than Ch.MDD, especially for the $\mathrm{pH}$ values less than the $\mathrm{pKa}$ of chitosan.

\section{DAF with Dual Coagulants Strategy}

\section{Dosing Sequence of PACl and Chitosan}

The primary concern of the dual-coagulant system was the dosing sequence of $\mathrm{PACl}$ and chitosan. There were also different opinions about this issue [27-28]. Focusing on this, a series of experiments were carried out under various raw water quality conditions at $[\mathrm{CH}]:[\mathrm{Al}]$ ratio of 0.2 following three dosing orders, such as adding chitosan or PACl first and adding them at the same time. For organic matter removal, an accordant conclusion could be drawn from the test results that dosing chitosan prior to $\mathrm{Al}$ salts was the most efficient. The DOC flotation rates according to other two dosing sequences were approximate to each other, and adding them at the same time was a little better than adding Al first. However, the situations became complicated for turbidity control. Many other factors including suspended solid load of the source water, mixing intensity and its duration, as well as flocs breakage and regrowth during this process, etc. - must also be taken into consideration. But one thing was certain: dosing chitosan after $\mathrm{PACl}$ was conducive to the aggregation of small size floc particles.

This research particularly emphasized organic matter removal by flotation. Thus, the subsequent dual-coagulant tests were performed by adding chitosan first, and then mixed intensively for 1 min prior to $\mathrm{PACl}$ dosing.

\section{Effect of [CH]:[Al] Ratios}

Fig. 6 shows the removal percentage of DOC and turbidity for HR water after flotation in a dual-coagulant strategy at different chitosan-to-aluminium concentration ratios. Using $\mathrm{PACl}$ alone, the removal of $84.5 \%$ turbidity was obtained at $\mathrm{Al}$ concentration of $4.5 \mathrm{mg} / \mathrm{L}$; beyond that it only slightly changed with further increase of Al dosage. There was a significant improvement in turbidity removal with the addition of chitosan, especially at low $\mathrm{Al}$ concentration. The coagulation aiding effects of chitosan on turbidity control were close to each other as the $[\mathrm{CH}]:[\mathrm{Al}]$ ratios varied from $0.2,0.4$, to 0.6 . At the $[\mathrm{CH}]:[\mathrm{Al}]$ ratio of 0.6 , when the $\mathrm{Al}$ concentration exceeded $2.8 \mathrm{mg} / \mathrm{L}$ the residual turbidity of floated water picked up slightly. Thus the lowest $[\mathrm{CH}]:[\mathrm{Al}]$ ratio of 0.2 was enough for a desirable particle separation.

With or without chitosan addition, the same change tendency was observed for DOC removal. At any specific Al concentration, the flotation efficiency increased gradually with the $[\mathrm{CH}]:[\mathrm{Al}]$ ratio growing from 0.2 to 0.6 . For example, at $[\mathrm{CH}]:[\mathrm{Al}]$ ratio of 0.4 , the removal rate of DOC increased by $5.2 \%$ and $7.7 \%$ with a low $\mathrm{Al}$ 
concentration $(1 \mathrm{mg} / \mathrm{L})$ and a moderate dose $(4 \mathrm{mg} / \mathrm{L})$, respectively.

\author{
Influence of DD and MW on \\ Chitosan Performance
}

\section{Molecular weight (Ch.MMW MDD versus Ch.HMW MDD)}

As illustrated in Fig. 7, MW and DD of chitosan played different roles in the dual-coagulant system. It is generally believed that polymers with a higher MW had the more remarkable bridging adsorption ability [29]. On the contrary, the present results showed that the increasing MW caused decreased flotation efficiency. This may be ascribed to the stronger affinity and more rapid interaction between Ch.MMW molecules and colloidal particles compared with the Ch.HMW ones. Similar results in previous research have also verified that the number of particles destabilized by low MW chitosan was higher than the high MW chitosan in the early stage after their addition [30].

\section{Deacetylation Degree (Ch.HMW MDD versus Ch.HMW HDD)}

Likewise, the stimulating effects of chitosan DD increasing from $76.5 \%$ to $87.8 \%$ on flotation efficiency was not as good as expected. Only marginal elevation of turbidity and $\mathrm{UV}_{254}$ removal was obtained.

By comparison, this indicated that when chitosan was used as a coagulant aid, the MW rather than the DD had a more pronounced effect on its flocculation performances. This finding agreed well with the results obtained by Chen et al. [31]. Notably, this didn't mean the insignificance of DD for chitosan, but instead indicated the complex raw water chemistry - especially the large quantities of blend ions that interfered with the effectiveness of increasing

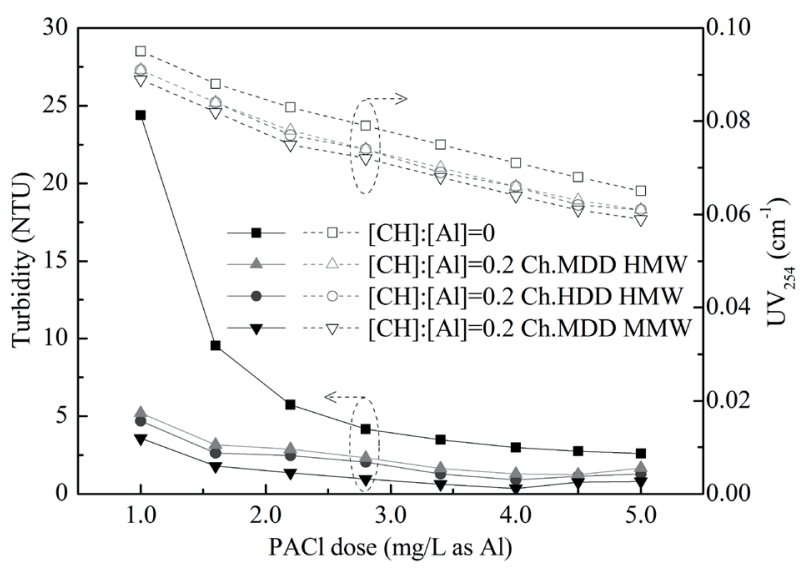

Fig. 7. Residual turbidity and $U_{254}$ after flotation in dualcoagulant strategies using chitosan with medium/high molecular weight (MMW or HMW) and deacetylation degree (MDD or HDD) (raw water quality: DOC $5.58 \mathrm{mg} / \mathrm{L}, \mathrm{UV}_{254} 0.125 \mathrm{~cm}^{-1}$, turbidity $62.3 \mathrm{NTU}, 24.6^{\circ} \mathrm{C}$; recycled water $\mathrm{pH}: 7 \pm 0.1$ ).
DD [32]. Besides, in the neural or weakly basic raw water, the protonating of amino groups was restricted by the shortage of $\mathrm{H}^{+}$. Without the addition of available $\mathrm{H}^{+}$, merely increasing $-\mathrm{NH}_{2}$ would only intensify the competition among plenty of amino groups and enhance the formation of intramolecular hydrogen bonds.

\section{Conclusions}

For conventional coagulation-DAF process, the introduction of chitosan, either as a coagulant aid or bubble surface modifier greatly improved the flotation efficiency of DOC, $\mathrm{UV}_{254}$ and turbidity. There was marginal difference of the DAF performances with chitosan used as coagulant aid and bubble modifier with recycled water $\mathrm{pH}$ at 7.0. The increase of DOC removal percentage varied between $4.3 \%$ and $8.0 \%$. The $[\mathrm{CH}]:[\mathrm{Al}]$ ratio of 0.2 was enough for desirable turbidity control. After the $\mathrm{pH}$ of the recycled water was adjusted to 5.5, the posi.DAF performed most efficiently. An obvious increase of $\mathrm{UV}_{254}$ removal was obtained from $32.4 \%$ at $\mathrm{pH} 7.0$ to $38.1 \%$ at $\mathrm{pH} 5.5$.

Recycled water $\mathrm{pH}$ value was a key external parameter for chitosan. The acidic recycled water with $\mathrm{pH}$ lower than the $\mathrm{pKa}$ of chitosan was favorable for posi.DAF. On the other hand, both the MW and DD were two important internal parameters for chitosan. Chitosan with high MW could be strongly bound onto bubble surfaces and led to high bubble modification efficiency. However, when chitosan was used as coagulant aids, medium MW chitosan performed more efficiently. By contrast, the influence of DD on chitosan flotation-aiding effects was complex and vulnerable to blended ions in raw water.

\section{Acknowledgements}

This research was funded by the National Natural Science Foundation of China (grant No. 51378141) and the Science and Technology Department of Heilongjiang Province, China (grant No. PS13H05). The authors gratefully acknowledge the friends of the Huainan First Water Treatment Plant for their full support to this research. Sincere thanks also go to our friends in the Central Laboratory of Huainan Capital Water for their great help in water sample analysis.

\section{References}

1. KHORSANDI H., BINA B., KHORSANDI J. Evaluation of $\mathrm{UV} / \mathrm{TiO}_{2}$ photo-catalytic process for removing humic compounds from water. Polish Journal of Environmental Studies, 24 (3), 1063, 2015.

2. SWIDERSKA-BROZ M., WOLSKAM. Effect of granulated active carbon bed regeneration on dissolved organic matter removal from surface water. Polish Journal of Environmental Studies, 24 (2), 717, 2015. 
3. SEVIK H., CETIN M. Effects of water stress on seed germination for select landscape plants. Polish Journal of Environmental Studies, 24 (2), 689, 2015.

4. SEVIK H., CETIN M., BELKAYALI N. Effects of forests on amounts of $\mathrm{CO}_{2}$ : case study of Kastamonu and Ilgaz Mountain national parks. Polish Journal of Environmental Studies, 24 (1), 253, 2015.

5. CETIN M., SEVIK H. Measuring the impact of selected plants on indoor $\mathrm{CO} 2$ concentrations. Polish Journal of Environmental Studies, 25 (3), 973, 2016.

6. CETIN M. A change in the amount of $\mathrm{CO}_{2}$ at the center of the examination halls: case study of Turkey. Studies on EthnoMedicine, 10 (2), 146, 2016.

7. CETIN M., SEVIK H. Change of air quality in Kastamonu city in terms of particulate matter and $\mathrm{CO}_{2}$ amount. Oxidation Communications, 39 (4-II), 3394, 2016.

8. MATILAINEN A., VEPSALAIENE M., SILLANPAA M. Natural organic matter removal by coagulation during drinking water treatment: a review. Advances in Colloid and Interface Science, 159 (2), 189, 2010.

9. ANTONYOVA A., ANTONY P. Mathematical modeling for optimizing the electro-flotation process of water treatment. Polish Journal of Environmental Studies, 24 (2), 483, 2015.

10. CETIN M., SEVIK H., ISINKARALAR K. Changes in the particulate matter and $\mathrm{CO}_{2}$ concentrations based on the time and weather conditions: the case of Kastamonu. Oxidation Communications, 40 (1-II), 477, 2017.

11. EDZWALD J.K., HAARHOFF J. Dissolved air flotation for water clarification. AWWA and McGraw Hill, New York, USA, 2012.

12. USEPA. Enhanced Coagulation and Enhanced Precipitative Softening Guidance Manual. EPA, Office of Water and Drinking Ground Water, Washington, D.C., USA, 20, 1998.

13. CARLSON K., VIA S., BELLAMY B., CARLSON M. Secondary effects of enhanced coagulation and softening. Journal American Water Works Association, 92 (6), 63, 2000.

14. FLATEN T.P. Aluminum as a risk factor in Alzheimer's disease, with emphasis on drinking water. Brain Research Bulletin, 55 (2), 187, 2001.

15. YAN M.Q., WANG D.S., QU J.H., NI J.R., CHOW C.W.K. Enhanced coagulation for high alkalinity and micro-polluted water: The third way through coagulant optimization. Water Research, 42 (8-9), 2278, 2008.

16. GAO B.Y., WANG Y., YUE Q.Y., WEI J.C., LI Q. The size and coagulation behavior of a novel composite inorganicorganic coagulant. Separation and Purification Technology, 62 (3), 544, 2008.

17. NG M., LIANA A.E., LIU S., LIM M., CHOW C.W.K., WANG D.S., DRIKAS M., AMAL R. Preparation and characterisation of new-polyaluminum chloride-chitosan composite coagulant. Water Research, 46 (15), 4614, 2012.

18. HAN M.Y., KIM M.K., SHIN M.S. Generation of a positively charged bubble and its possible mechanism of formation. Journal of Water Supply: Research and Technology AQUA, $55(7-8), 471,2006$.

19. HENDERSON R.K., PARSONS S.A., JEFFERSON B. Polymers as bubble surface modifiers in the flotation of algae. Environmental Technology, 31 (7), 781, 2010.
20. KARHU M., LEIVISKA T., TANSKANEN J. Enhanced DAF in breaking up oil-in-water emulsions. Separation and Purification Technology, 122, 231, 2014.

21. YAP R.K.L., WHITTAKER M., DIAO M., STUETZ R.M., JEFFERSON B., BULMUS V., PEIRSON W.L., NGUYEN A.V., HENDERSON R.K. Hydrophobically-associating cationic polymers as micro-bubble surface modifiers in dissolved air flotation for cyanobacteria cell separation. Water Research, 61, 253, 2014.

22. RAO N.R.H., YAP R., GRANVILLE A.M., STUETZ R.M., HENDERSON R.K. Algae flotation using PosiDAF: A comparison of polymers as bubble surface modifiers. In: Proceeding of the 7th International Conference of Flotation in Water and Wastewater Systems. Toulouse, France, 168, 2016.

23. ZHANG M., GUIRAUD P. Colloidal gas aphrons in flotation separation of nanoparticles: bubble dispersion features and flotation performance. In: Proceeding of the 7th International Conference of Flotation in Water and Wastewater Systems. Toulouse, France, 134, 2016.

24. SHI Y.L., YANG J.X., MA J., LOU C.W. Feasibility of bubble surface modification for natural organic matter removal from river water using dissolved air flotation. Frontier of Environmental Science \& Engineering, 2017 [Accepted].

25. RENAULT F., SANCEY B., BADOT P.M., CRINI G. Chitosan for coagulation/flocculation processes-An ecofriendly approach. European Polymer Journal, 45 (5), 1337, 2009.

26. KAM S. K., GREGORY J. Charge determination of synthetic cationic polyelectrolytes by colloid titration. Colloids and Surface A: Physicochemical and Engineering Aspects, 159 (1), 165, 1999.

27. GUIBAL E., VOOREN M.V., DEMPSEY A.B., ROUSSY J. A review of the use of chitosan for the removal of particulate and dissolved contaminants. Separation Science and Technology, 41 (11), 2487, 2006.

28. HUANG X., GAO B.Y., YUE Q.Y., WANG Y., LI Q., ZHAO $\mathrm{S}$. Effect of dosing sequence and raw water $\mathrm{pH}$ on coagulation performance and flocs properties using dual-coagulant of polyaluminum chloride and compound bioflocculant in low temperature surface water treatment. Chemical Engineering Journal, 229, 477, 2012.

29. LI J., SONG X.Y., PAN J.F., ZHONG L., JIAO S.F., MA Q.M. Adsorption and flocculation of bentonite by chitosan with varying degree of deacetylation and molecular weight. International Journal of Biological Macromolecules, 62, 4, 2013.

30. MIRANDA R., NICU R., LATOUR I., LUPEI M., BOBU E., BLANCO A. Efficiency of chitosans for the treatment of papermaking process water by dissolved air flotation. Chemical Engineering Journal, 231, 304, 2013.

31. CHEN L., CHEN D.H., WU C.L. A new approach for the flocculation mechanism of chitosan. Journal of Polymers and the Environment, 11 (3), 87, 2003.

32. LI J., JIAO S.F., ZHONG L., PAN J.F., MA Q.M. Optimizing coagulation and flocculation process for kaolinite suspension with chitosan. Colloids and Surface A: Physicochemical and Engineering Aspects, 428, 100, 2013. 